\title{
Legibility on a Podcast: Color and typefaces
}

\author{
Lennart Strand \\ Mälardalen University \\ Information Design, IDP \\ Box 325 \\ 63105 Eskilstuna, Sweden
}

\begin{abstract}
As in printed matter, black text on white background is the most legible color combination on small computer screens like media players.
\end{abstract}

\section{INTRODUCTION}

Color - on type and background - significantly affects legibility, both in print and on computer screens.

Reference [1] writes that the most important consideration when working with type and color is to achieve an appropriate contrast between type and its background (p. 80, 2007):

"It has long been considered that black type on a white background is the most legible (combination). While this combination remains an excellent choice, other alternatives may offer equal if not improved legibility due to improved digital and printing technologies, and the fact that color is a relative phenomenon.

Generally, all legibility guidelines related to working with color and type in print apply also to type appearing on a computer screen.”

Reference [2] writes that a text on a computer screen must have good legibility, and that information designers should use typefaces designed for screen display, such as Trebuchet and Verdana. ("It Depends: ID - Principles and Guidelines", p. 2425, 2007).

Reference [3] writes that the background color on a computer screen should be fairly light or fairly dark, depending on the content. The text should have an opposite color, fairly dark or fairly light color. The best combination is black text on white or yellow background.

Reference [4] found, in a study about airport signage, that black text on a yellow background is superior as compared to white on black, white on grey and black on white.

Reference [5] studied the effects of six foreground/background color combinations, three fonttypes (Arial, Courier New, and Times New Roman), and two wordstyles (italicized and plain) on legibility of websites.
"Participants scanned simulated websites for a target word; readability was inferred from reaction time (RT). In general these results suggest that there is no one foreground/background combination, font, or wordstyle which leads to the fastest RT (i.e. best readability), but rather a designer must consider how each variable affects the other(s)."

Note: the word "readability" in the reference 5's study has the same meaning as "legibility" in this study.

\section{SMALL COMPUTER SCREENS}

In order to find out how color affects legibility and reading comfort on small computer screens on mediaplayers that can show videofilm, like an Apple iPod, I have asked students in information design at Mälardalen University in Eskilstuna, Sweden, to study:

- five color combinations, typeface and background

- five different typefaces

- bold and regular typefaces

- lower case and upper case type

For the study I used an Apple iPod-screen, measuring 40 mm x $52 \mathrm{~mm}$. Alternatively the examples could be studied as a video cast measuring 50 x $66 \mathrm{~mm}$ on a 17 -inch computer screen.

The text varied in all five examples, but the number of textlines were the same, four in all examples.

The subjects were asked to study the color combinations thoroughly for legibility:

Take all the time you need. Then rank the combinations on a scale from 1 to 5 . Number 1 is the combination that you find the most comfortable to read on the iPod-screen. Number 5 is the combination that is the least comfortable for you to read on this small computer screen.

The color combinations were:

Black on yellow background

Yellow on black

Yellow on dark brown

Black on white

White on black 
The typeface - Verdana Bold 50 points - was in this study the same on all of the tested backgrounds.

In addition five different typefaces were studied for legibility on the same iPod-screen. The typed text was the same in all five examples, in order for the subjects to be able to concentrate on the typefaces. Text was black on yellow background.

The subjects were asked to study the typefaces thoroughly: Take all the time you need. Which one of these five typefaces are most comfortable for you to read on the iPod-screen?

Please take your time and study each typeface thoroughly. Then rank them on a scale from 1 to 5 , with 1 as the type face that you find the most comfortable to read on this small computer screen and with 5 as the one that is the least comfortable for you to read.

\section{The typefaces were: \\ Verdana Bold \\ Georgia Bold \\ Futura Bold \\ Helvetica 75 Bold \\ Frutiger 65 Bold}

The type size here was also 50 points.

I used bold typefaces in my examples in this study, though reference [6] in a study about headings in print, (Rubriker, p. $45-47,2003$ ), found that regular or normal type was easier to read than bold typefaces. Because of this recommendation I also asked the subjects to compare Verdana Bold with Verdana Regular on the iPod-screen; I then asked the subjects to write down what to them was the easiest typeface to read - bold or regular.

The subjects were also asked to study - on the same iPodscreen or computer screen - one paragraph typed in lower case type, and the same paragraph typed in upper case type. The number of textlines were four, the typeface used was Verdana Bold 50 points.

The subjects were then asked whether they prefer lower case type or upper case type on this small computer screen.

Subjects were also asked to mark their answers with an F for females, and with $\mathrm{M}$ for males.

All subjects in this study were under 30 years of age.

\section{THE ANSWERS}

Over all, 93 students participated in the project. They were asked to carefully study the various variations, and rank them on a scale from 1 to 5 , with 1 as the most preferred example, and 5 as the least preferred example.

In order to get as close as possible to the overall preferred examples I combined ranks 1 and 2. I did this because some subjects had a difficult time to chose between 1 and 2 .
A. Five color combinations - type and background; which color combination is most comfortable for you to read?

33 subjects found black text on white background had good legibility and that this color combination was most comfortable to read on a small computer screen, out of the five examples. 25 subjects felt that white text on a black background was the most comfortable combination to read on a small computer screen.

Answers 1+2 combined:

Black on white 33

White on black 25

Black on yellow background 15

Yellow on black 14

Yellow on a brown-reddish background 6

B. Which typeface is most comfortable for you to read?

Out of the five typefaces tested 30 subjects of 92 found Frutiger 65 Bold to be the most comfortable typeface to read on a small computer screen. 24 subjects found Helvetica 75 Bold to be the most comfortable typeface to read on a small computer screen.

\section{Answers $1+2$ combined: \\ Frutiger 65 Bold 30 \\ Helvetica 75 Bold 24 \\ Verdana Bold 21 \\ Georgia Bold 10 \\ Futura Bold 7}

\section{Do you prefer bold or regular type?}

The typeface used here was Verdana, designed for screen.

27 of 46 subjects found it easier to read a regular typeface than a bold typeface. 19 subjects preferred bold typeface.

\section{Answers:}

Verdana Regular 27

Verdana Bold 19

\section{Do you prefer lower case type or upper case type?}

The typeface here was also Verdana.

45 of 47 subjects found it easier to read lower case type compared to upper case type

Answers:

Lower case type 45

Upper case type 2

E. What number of textlines are the most comfortable for you to read on a small computer screen like an iPod?

17 subjects preferred 4 textlines

11 subjects preferred 3 textlines

11 subjects preferred 5 textlines

There were no significant differences between men and women. 


\section{CONCLUSION/RECOMMENDATION}

The traditional choice, black type on white background is a good choice for a color combination on small computer screens like iPods. As is regular type, and lower case type. Four is the preferred number of textlines.

\section{REFERENCES}

[1] R. Carter, B. Day, P. Meggs, ”Typographic Design: Form and Communication. Fourth Edition. Hoboken, New Jersey, USA: John Wiley \& Sons, Inc. 2007.
[2] Pettersson, R, ”It Depends: ID - Principles and Guidelines,” Tullinge, Sweden: Institute for Infology. 2007.

[3] Bradshaw, A. C. ”Evaluation Visuals for Instruction,” In R.E. Griffin, W.J. Gibbs \& V.S. Villiams (Eds.) 2000: Natural Vistas Visual Literacy \& The World Around Us. Selected Readings of the International Visual Literacy Association. International Visual Literacy Association.

[4] Waller, R, ”Comparing typefaces for airport signs,” Information Design Journal Volume 15 number 1, 2007 p. 1-15. Amsterdam/Philadelphia: John Benjamins Publishing.

[5] Hill, A, (supervised by Scharff, L. V.) "Readability of screen displays with various foreground/background color combinations, font styles, and font types,” 1997. Retrieved 2007-08-24.

[6] Pettersson, R, (2003). ”Rubriker,” Stockholm: Stiftelsen Institutet för Mediestudier, 2003. 